Emerging identities of adult language learners in their

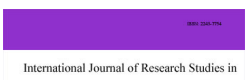
socialization in ESL programs

Kim, Juhi

Ohio State University, USA (kim.2487@osu.edu)

\title{
Abstract
}

With the spread of English as a global language, an increasing number of Korean international students are coming to the U.S. to learn English. Those who have different life experiences in Korea in terms of age, job, and motivation for learning English socialize themselves to American educational institutions in various ways. This paper examines how Korean adult English learners who came from various backgrounds socialize themselves from their English learning experience in American ESL programs, and how they construct new identities in their language learning socialization process to obtain social memberships.

Keywords: learner identity; language socialization; ESL program; adult language learner; Korean sojourner 


\section{Emerging identities of adult language learners in their socialization in ESL programs}

\section{Introduction}

Every year, an increasing number of Korean learners from different backgrounds, both personal and social, come to the United States to learn English. Recently, the number of Korean learners who worked as professionals has increased in the American ESL programs. Some of them come with all of their family and some come with only their children, a "Gerogi" family. Cultural differences and language difficulties hinder these learners from expanding their social circles. In particular, those who had worked as professionals in Korea experience serious identity loss with culture shock at the beginning of their stay. The identity struggle between their pre-established, full member identity in their own society as professionals and their new-comer identity in a foreign country influence their socialization to American educational institutions.

In this regard, it is necessary to investigate how Korean students develop relationships to construct social networks in order to adjust themselves to this new environment. Considering language as a social interaction, it is essential to examine how they construct social and cultural networks to enhance their language ability and what they actually experience in terms of learning English and making social interactions. The difficulties they encounter on the way of adjusting, how they construct social networks, and ultimately how they perceive themselves in terms of language and membership (which is closely related with identity through the interaction in which they are engaging) will be investigated.

Language corresponds to one's values, beliefs and social identities and constructing a new identity involves obtaining social membership (Sfard \& Prusak, 2005). Identity formation in second language acquisition is a continuing and developing process influenced by various socio-cultural factors. These socio-cultural factors that have a significant influence on the language learners' identity formation will contribute to the process of successful language learning.

In this regard, continuing from the study of Korean international students' socialization and language learning experiences in American ESL programs (Kim, 2008), this paper investigates the development of Korean adult students' emerging identities as "New-Comers" in American ESL programs (Lave \& Wenger, 1991), how they negotiate their status as "New-Comers" in relation to "Old-Timers", how they deal with the distinction between "actual" and "designated" identity, and ultimately, how their identity formation influences the path of their lives and plans. By conducting interviews and making classroom observations, this paper will focus to investigate the process of their socialization to U.S. educational institutions and the change in their perceptions of language and identity.

\section{Literature review}

\subsection{Language learning and social identity}

Identity is a term that refers to "how a person understands his or her relationship to the world," "how that relationship is constructed across time and space," and "how the person understands possibilities for the future" (Pierce, 1997). Thus, identity should be understood within the context of larger, inequitable social structures and power relations that are produced by daily social interactions (Peirce, 1995). In this sense, second language learners would experience the conflict of their identity in the process of language socialization.

Heller (1987) suggested that second language learners negotiate a sense of self within different sites at different points in time through language to access powerful social networks that can provide them with the opportunity to speak. Cummins (1996) also mentioned that power is not a predetermined quantity but can be 
mutually generated with others in interpersonal and intergroup relations. From this point of view, identity is closely related with relations of power that are negotiated in classrooms and communities. In this regard, language is not a neutral medium for communication, but a reference to its social meaning. (Peirce, 2000) Language learning should be understood on the basis of social interactions, and mutual interactions in society always involve power relations.

\subsection{Power relations in classroom interaction}

Bloome, Carter, Christian, Otto and Shuart-Faris (2004) discussed a model of power in three ways: power as a product, power as a process and power as a caring relation. The definition of power as a product lies in the validity of "the context of people's lives - people act, value, feel, believe, think, and use language" in a paradigm of market economy. It cannot exist outside an ideology of social relationship, which is closely associated with a market economy. Literacy, in this sense, can be defined as power as a product. When literacy is viewed as skills in the classroom, which are visible, measurable, and transferrable, it becomes a tool that represents strength and controls power (Bloome et al., 2004).

The definition of power as a process views power as a set of relations among people and social institutions which can be shifted from one institution to another (ibid). From this perspective, power is a process of structuring relationships among people. Power is dialogic, in which people always negotiate and compromise to contribute to the process of power (ibid). Power relations in this sense are aligned with socio-cultural practice, and those practices are an essential part of daily experiences.

Power as a product in a classroom setting can be exemplified by "gaining various skills" in school that can be transformed into social status (good grade, school awards, etc.) and economic access (admission and promotion) (ibid). Power as a process is the "naturalization of a discourse and a culture" (ibid, p.163). This hegemony privileges some words, languages and cultures by making them look natural and marginalizing other types of words and other languages as unnatural and unauthorized forms of discourse. Naturalization makes the distinction between normal and abnormal, common and uncommon, and acceptable and unacceptable. Especially, the distinction between "us" vs. "them" can marginalize the "other," as powerless objects.

The perspective on power as caring relations views power as "the potential to bring people together for mutual benefit, both with regard to social relationships and with regard to other accomplishments" (ibid, p.165). This model views power as a mutual and reciprocal process that involves action, effort, achievement, respect, and responsiveness (ibid).

Power relations are constructed by a market economy as a product of the social relationships of individuals and institutions toward mutual benefit and accomplishment. In this sense, knowledge in the scene of power struggles involves identity building. The stance toward understanding what is valid knowledge and who has the authority for validating knowledge as experts and novices, students and teachers, New-Comers and Old-Timers, and insiders and outsiders is crucial for building one's identity. Examining how knowledge is transformed into extant power through language use between people within institutions is essential for revealing power relations in the classroom.

\subsection{Power, resistance, and identity construction}

Identity has been defined in various ways by different scholars. Gee (2001) defined identity as a certain "kind of person" in a given text and differentiated it in terms of four different power sources: Nature-identity, Institution-identity, Discourse-identity, and Affinity-identity. He also distinguished "achieved identity" from "ascribed identity" as elites from non-elites identity in Discourse Identity, which he defined as "ways of being certain kinds of people".

He argued that what is an issue in identity is who and by whom the identities are recognized. Individuals try 
to get recognition from others; however, in modern capitalist societies, non-elites are "encouraged" to accept their inferior identities that elites assign them in talk and interaction (discourse) and accept the elites superior identities as an "achieved identity" that has resulted from their own effort in a fair competition (Gee, 2001). Explicit and implicit resistance of identity struggles of individuals are involved in the appellation of social identity. Although Ivanic (1998) noted the possibility of resistance in "contesting dominant constructions of the self," it is difficult for individuals to contest "ascribed identities" and the social positions assigned to them because of the view that social construction of identity is influenced by dominant ideologies in controlling people's sense of themselves (Bloome et al., 2004, p. 140). Walkerdine (1990) suggested a more empowering view of resistance as potentially revolutionary power, not just a struggle against the dominating power. Resistance in power relations is continually reproduced, in a continual struggle shifting (Walkerdine, 1990, p.4, ibid).

As regards to the definition of identity of Gee (2001), Sfard and Prusak (2005) encapsulated the notion of identity in the "activity of communication, which is conceived broadly as self-dialogue" (p. 16, cited in Sfard \& Prusak, 2005) and embraced identity-making as a "communication practice" (ibid).

Sfard and Prusak (2005) suggested the triple ${ }_{B} A_{C}$ to describe the story of an identified person. The three types of the story of identity, ${ }_{A} \mathrm{~A}_{C}$ (A's first-person identity), ${ }_{B} \mathrm{~A}_{\mathrm{A}}$ (A's second-person identity), and ${ }_{B} \mathrm{~A}_{\mathrm{C}}$ ( $\mathrm{A}^{\prime} \mathrm{s}$ third-person identity) show the various aspects of one's identity. Among them, ${ }_{A} A_{A}$ (the first-person, Self-told identity) is the core of one's identity that affects one's actions. However, Wenger (1998) stated the significance of one's experience and engagement in practice as following:

We often think about our identities as self-images because we talk about ourselves and each other- and even think about ourselves and each other in words. These words are important, no doubt, but they are not the full, lived experience of engagement in practice (p. 151, as cited in Sfard \& Prusak, 2005).

The experience of one's storytelling of their identity is not just a source of identifying their storytelling, but also the activity's natural outcome. Sfard and Prusak also introduced "actual identity: stories about the actual state of affairs" and "designated identity: stories presenting a state of affairs that are expected to be the case in the future" (ibid, p.18). Learning occurs to fulfill the gap between actual identity and designated identity.

Through intertextual, intercontextual connection, and interdiscoursivity of individual's contexts in present, past and future among social events, individuals constantly negotiate and compromise their identities for resisting the hegemony of the dominant society. In this paper, the researcher will investigate how Korean students' emerging identities are represented and negotiated in the field of language education with their interaction with the teacher and classmates through the lens of ethnographic discourse analysis.

\section{Research questions}

This study examines how Korean students construct social networks and build their identities through language socialization in American ESL programs; how they negotiate their status as "New-Comers" in relation with "Old-Timers"; how they deal with the distinction between "ascribed" and "achieved" identities; and ultimately, and how their new emerging identities influence their lives and plans.

1. How do Korean students negotiate their identity as new comers in terms of power relations in an ESL classroom?

2. How do Korean students perceive themselves and react a) "ascribed" vs. "achieved" identities, and b) "actual" and "designated identities"?

3. How do their new identities emerge and influence the paths of their lives and plans in the process of their socialization to the U.S.? 
Through investigating the research questions, the researcher will examine the interactional discourse in an ESL classroom and how the students perceive their emerging identities in their socialization process with respect to their new emerging identities

\section{Methodology}

\subsection{Participants and research setting}

This study was conducted at an American Language Program, located at a Midwestern University in the U.S., where there are five levels of classes for English proficiency. The students for this study were chosen from the highest level of the class. They met Monday through Friday, from 8: 30AM to 2: 20 PM. In the morning, from 8:30 AM to 11:20, they met in the same classroom with Anna (pseudonym), the American female teacher who has been teaching international students for several years and has studied the integrated skills of English. In the afternoon from 12:30PM to 2:20 PM, they studied English grammar and elective courses (TOEFL, SAT preparation, American films, etc.).

Four Koreans, two male and two female students in level 5, participated in this study. The two female students were college students, aged 20 and 22. The two male students were in their mid-thirties and were originally businessman in Korea. Dongseok was a very capable businessman with a promising company in Korea for about ten years and was pursuing doctoral studies majoring in business, beginning in the next quarter. Hyungsoo was a businessman in Korea and he came to the U.S. for learning English with the support of his company 10 months ago. All participants were born in Korea and learned English as a foreign language in their secondary school.

\section{Table 1}

Participants of the study

\begin{tabular}{lll}
\hline \multicolumn{1}{c}{ Participants } & \multicolumn{1}{c}{ Length of Stay } & \multicolumn{1}{c}{ Occupation in Korea } \\
\hline Jia (female, 20) & 3 months & College student \\
Mirae (female, 23) & 10 months & College student \\
Dongseok (male, 36) & 3 months & Businessman (for ten years) and a doctoral student \\
Hyungsoo (male, 37$)$ & 10 months & businessman (for ten years) \\
\hline Note. All names are pseudonyms & &
\end{tabular}

\subsection{Data collection}

The researcher visited the class three times a week, Monday, Wednesday, and Friday, from 10:30AM to 11:20AM for seven weeks. The researcher sat behind the class and observed their classroom events and wrote field notes. The researcher was introduced to the class and shared the purpose of the study in the first day. The researcher conducted two semi-structured interviews with the participants: a group interview with two participants in the beginning of the observation and individual interviews with each participant in the end of the observation. The interviews were conducted in Korean language and recorded by digital audio recorder. Informal talks with the instructor and other international students were conducted for methodological triangulation.

\subsection{Data analysis}

Field notes from the class observations and recorded data from the interviews were analyzed through the lens of critical micro-ethnographic discourse analysis. The model of power discussed by Bloome et al. (2004) and the discourse of identity by Gee (2001) and Sfard and Prusak (2005) were employed for the theoretical framework of this study. 


\section{Findings}

\subsection{Dongseok}

Dongseok is a 36-year-old male student. He came to the U.S. three months ago to prepare his English for his doctoral study. He came early to improve his English in ALP before he begins doctoral study. He was a competent businessman in a promising company in Korea. Also, he was a student in doctoral program in Korea. In the first meeting, he gave me his Korean business card on which was typed his association in Korea. He seemed very busy. He said that he could not make a time for my research and was not willing to join my study. The researcher was able to see the reason in the first interview. The interview was conducted in Korean.

Episode 1: The first interview (translated into English)

\begin{tabular}{|l} 
The researcher: While you are taking classes here= \\
Dongseok
\end{tabular}$\quad \begin{aligned} & \text { admitted for autumn quarter........... The problem here is my social status I came here with } \\
& \text { my family, but there is nothing I can do by myself as a foreigner....... I am not that poor at } \\
& \text { English originally but here, I don't speak English well...Actually, there is no difficulty in } \\
& \text { studying English here, but living by itself is difficult. Since I am with my family I have to go } \\
& \text { back home around } 3 \text { or } 4 \text { pm to be with my wife and a kid. I can't spend time for only } \\
& \text { myself. }\end{aligned}$

He cut off my initiating statement, introducing his associated institution in school. He talked about his previous works in Korea and expressed his difficulty of English and his status as a foreigner. He was already experiencing frustration caused by the discrepancy between his positionality as a competent member in Korea and a newcomer in a foreign country.

Episode 2: Arguing with an Arabic student about group presentation.

When the researcher entered the classroom, Dongseok was arguing with Amid; a 26- year old Arabic man who has been in the program for a while, standing in front of the class. Dongseok had just finished his presentation. Amid was giving his comments to him. Dongseok seemed to get angry. Dongseok was yelling at Amid.

$$
\begin{array}{ll}
\text { Amid } & :( \\
\text { Dongseok } & : \text { You try to teach me? } \\
\text { Amid } & : \text { No. I am just talking my opinion.( } \\
\text { Dongseok } & : \text { // You think I am dumb? I AM NOT DUMB! }
\end{array}
$$

Anna came to the class and asked them to calm down and take some cool air outside. After class, both were summoned to see Anna. The researcher got the chance to talk with Dongseok about the incident later. Dongseok said that Amid was rude in giving his comment and said,

"He apologized to me. He always finds fault with others. Everybody knows it and nobody wants to work with him....... They (Arabic students) are basically not responsible. They are just like that. You know, they talk a lot in class, but their English is bad... I do usually everything when we have a group work. They can't do well in reading and writing."

Dongseok criticized the Arabic students as irresponsible and incompetent in reading and writing, but their 
oral proficiency was more fluent than the Korean student in the classroom. Dongseok did not mention their strengths. He just criticized their attitude and verbosity. Their high oral proficiency was devalued as being talkative, and their active engagement in the classroom activities were downgraded as faultfinders and troublemakers.

This exhibits the existence of power struggles between the two groups, Korean students and Arabic students, in terms of the market economy based on the model of "power as a product (Bloome et al., 2004)" which is going on in the classroom.

Regarding the argument between Dongseok and Amid, Anna gave her interpretation later. She said, "Dongseok is expecting a kind of respect in terms of his age from the younger students as it was in Korea. But the students from different countries do not respect older people just because they are old." Dongseok was threatened by the collision between his value, belief and identity and the new value system which is totally different from Korea in an unexpected way.

Episode 3: Listening comprehension practice

\begin{tabular}{|ll|}
\hline Anna & Okay(.) business people? I need \\
& Dongseok? Do you remember? \\
Dongseok : & $(3.0)$ \\
Anna & $:$ Because it is English (,)it's not //weird if you don't remember. \\
Dongseok $:$ & // I don't know the word, what utility is in Korean. $=$ \\
Anna $\quad:=$ & Okay, its okay. Does anybody know what utility means?
\end{tabular}

As it is shown in the discourse, Anna tried to give validation his knowledge to connect and maintain his expertise and his actual identity (Bloome et al., 2004, p. 194). Dongseok here did not show any embarrassment of not knowing the meaning of "utility". He cut off Anna's face-saving statement and answered that he does not even know what it means in Korean language, which shows that the word, "utility" may not be the terminology of business, and even if it is, he does not know the meaning of the English word, "utility".

Dongseok talked about himself and his English by using the technique of " $1{ }^{\text {st }}$-person identity ( ${ }_{\mathrm{A}} \mathrm{A}_{\mathrm{C}}$ )" in the first interview (Sfard \& Prusak, 2005). He said, "I was not the person who is poor at speaking English but now I compare my English with native speakers." Though it has been just three months, he was experiencing the difficulty resulting from conflict between his expectation and reality. He also began to compare his English with native speakers and was discouraged by that. However, in the description of the Arabic students, he showed his superiority over others including other Korean students in terms of his socio-economic status (SES) and age.

He talked a lot about his previous work and company, especially about his past achievement in Korea. He talked about the intimate relations with his boss in Korean company. He also talked about his advisor in his department and said, "My advisor asked me if I play golf in the first meeting with me. You know, it is different treatment by itself from those who studies in ALP." Dongseok continuously talked about how his professor treated him differently and how his previous boss treated him differently. In this way, he showed his $2^{\text {nd }}$ person identity ${ }_{(\mathrm{B}} \mathrm{A}_{\mathrm{A})}$ to provide evidence of which he is (Sfard \& Prusak, 2005).

Regarding his third-person identity $\left({ }_{\mathrm{B}} \mathrm{A}_{\mathrm{C}}\right)$, Anna said that Dongseok seemed to expect a similar respect from other people regarding his age at least. When Dongseok was arguing with Amid, Dongseok was angry at Amid's attitude when he was pointing out several faults of Dongseok's presentation.

Dongseok clearly differentiated himself from other classmates and put himself in a superior position to them in terms of his age, financial status, working experience and former social status in Korea. However, in spite of his efforts, the same difficulties that he encountered as a New Comer in the U.S. made him frustrated. His value 
Kim, J.

in the model of power as a product was not valued as he was expecting. His socio-cultural capital was not recognized as power in the ESL classroom as the power in their classroom was already established by the certain, naturalized standard that Dongseok has not been able to reach at this moment. He tried to maintain his identity to be recognized by others by showing his past, present and his potential.

In regard to his social networks, he seemed to make an effort to expand his social networks as large as possible with other professionals in the level he desired to belong (designated identity). He decorated himself with his socio-cultural capital. He did not try to admit the "ascribed identity" that he is facing. He was fighting against them and vigorously resisting them in and out of the classroom. He might already have experienced the "ascribed identity" in himself during the time of his initial socialization as a novice learner.

\section{$5.2 \mathrm{Jia}$}

Jia was the youngest member in this class. She completed one year in Korean university and came to the U.S to learn English two months ago. She talked about the difficulty of communicating in English with her roommate and classmates despite the fact that she was assigned to level 5 in her first quarter in this program. She was being helped by the Korean religions community in her initial settlement. Since she had no car and no experience of living by herself, she was almost always being helped by other people, mostly Korean friends, to solve some daily problems.

Jia talked about the problems that she encountered in relations with her American roommate. She was already experiencing the difficulty and frustration resulting from her language deficiency and cultural ignorance in the relation with her American roommate. Jia was angry with the way that the American roommate asked her to do the house chores but she never expressed her anger to her roommate, though she thought her roommate was rude and her request was unfair. Jia was experiencing her inferior status, arguing the issue with her American roommate in English. She was on the edge of realizing her different social position in terms of language skills. She wanted to argue with her roommate about the unfair division of house chores, but it was difficult for her to initiate arguing with her roommates in English by herself. As Bloome et al. (2004) discussed, she talked to other Korean friends who might have been able to help her or advise her about how to solve the problems.

As Ivanic (1998) mentioned, "individuals contesting the dominant power have potential for producing change" (p. 13). Jia expressed her anger and unpleasant feelings toward her American roommate as evidence of resisting the hegemonic superiority of the English dominated community. However, the recognition of her lack of power in terms of market economy let her remain silent in the field of power struggles.

In class, she never volunteered either asking questions or giving answers. Even when she was asked by the teacher, she sat in silence without a word. In group discussions, she preferred listening to other classmates, rather than expressing her idea. She sat mostly near the other Korean students. After class or during the break, Jia usually stayed with another female classmate.

Jia said that she wants to experience another university or travel to other countries. Since she is already at the highest level in her first quarter, she said studying in this program for the rest of the year at the same level would be a waste of time.

\subsection{Hyungsoo}

Hyungsoo came to the U.S. with his wife and 4-year-old son ten months ago. He was a businessman in a trading company. He came to study English with the support of his company. But he did not seem to plan to go back after this program. He said that he will apply for graduate school to pursue a Master's degree. 
Episode 1:

The three students, Hyungsoo, Inae (23, Korean female) and Karif (24, Arabic male) are in the same group.

They are talking about their group presentation.

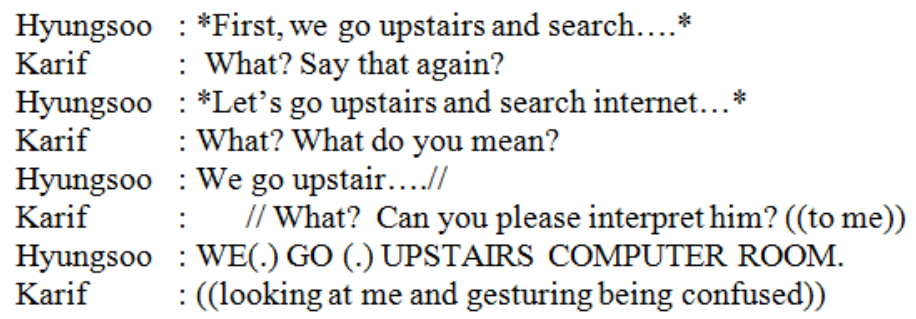

Karif's behavior was very rude to Hyungsoo from my perspective. But Hyungsoo patiently repeated his sentence to Karif without showing any anger or uncomfortable emotions. When he was asked about Arabic students, he answered,

"They are always like that ((laugh)). Sometimes they seem like rude but I think it is like their culture. I don't much care about it."

He seemed to compromise the reality in the classroom in a certain way.

\section{Episode 2:}

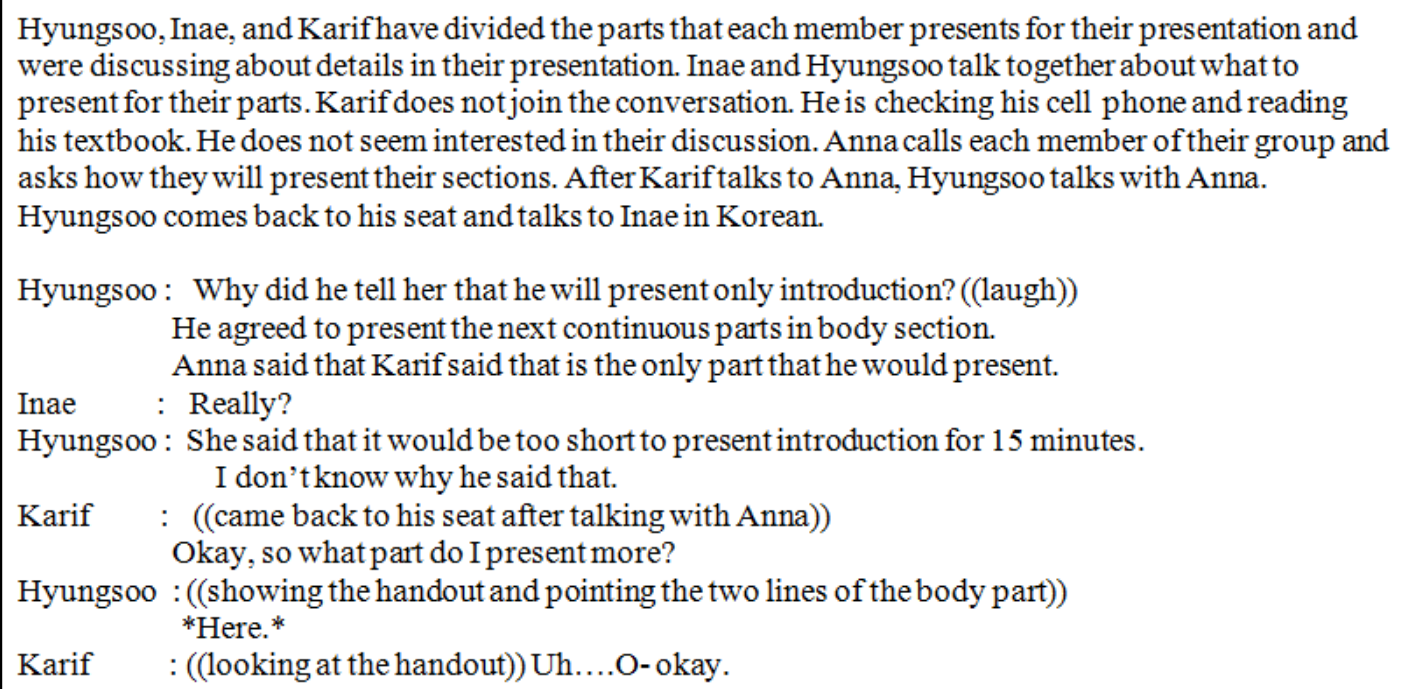

Again, in this situation, Hyungsoo did not show the uncomfortable feeling toward Karif externally in any case. When the researcher asked him what he thinks of Karif's negligence of group work, he said,

"I am not that sensitive by nature. ((laugh)) I don't much care the way that other people behave. It is just their way of doing. I don't much think about that."(Hyungsoo, 37; Korean male)

And he continued,

"You know, they talk a lot in the class. So, I thought they speak very well at first, but they just enjoy talking and arguing. You know, usually, we (Korean) prefer not to express our idea in the 
classroom whether we know the answer or not. But they are not like us. So I don't much care what they are talking. I just do things I need to do and if they don't as a member of group, I just do their parts by myself." (Hyungsoo, 37; Korean male).

Anna mentioned his personality in informal talks with me regarding his description of himself, which was that he is a shy and introverted person by nature. When the researcher asked about the improvement of his English, he answered with a laugh, "I hoped to improve my English skills but things improved here in the U.S. are my weight only."

The researcher noticed that Hyungsoo and Dongseok were not willing to participate in this study at the beginning. Especially, whenever the researcher asked Hyungsoo a question that might touch his inner self, he transformed the question into a joke and made fun of himself, as was shown in his remarks about his English. His strategies to deal with the various events in the classroom were ignoring the facts that may have caused trouble for him internally and externally. He rejected confronting the conflicts that may have occurred in and out of the classroom by ignoring them or making fun of him. His strategies seemed somehow passive compared to those of Dongseok. It was his own way to resist the power controlling and dominating him and protect his own identity within the boundary that he could control.

What Dongseok and Anna said about Hyungsoo $\left({ }_{B} A_{C}\right.$, third person identity) were the same things he described himself as he did not reveal his feelings externally even to Dongseok, the only other Korean male. Hyungsoo did not try to make any extra close relationship with Anna as Dongseok did. Instead, he was getting along with Inae, the younger female student in the classroom and did not make much interaction with other international classmates.

In terms of his second-person identity $\left({ }_{B} A_{A}\right)$, he did not mention what he heard from others in Korea; but in the U.S., he mentioned briefly what he heard from other people.

"Foreigners (not Korean) do not much care about what I am doing. But when I tell other Koreans that I am studying English in ALP, they respond in a sympathetic way. It seemed like that they feel pathetic about me."

In a similar context, he said that he does not go to the Korean church as often as he used to go. He was afraid of talking about the Korean church. It seemed that he was being careful of the rumors and gossip in the Korean community. He was reluctant to talk more about the Korean church. To the question about his social networks, he answered "School and home at this moment. That's it." Not only because of his language deficiency and the cultural differences in the U.S. but also the restriction from his position to the social network, he seemed to accept the "ascribed identity" (Gee, 2001) somehow. However, he was constantly resisting the "ascribed identity" in his own strategies and tried to get the "achieved identity" with the concrete, visible evidence, such as admission to graduate school. To the question of how he dealt with the difficult moments in the U.S. caused by his language proficiency, he answered "Well..., it's okay since it (my resistance) has not ended yet..." He was waiting for admission to graduate school.

\subsection{Mirae}

This quarter was her third quarter. She said that she will go back to Korea this summer. She did not much interact with the other Korean classmates in the classroom and usually sat near the Arabic students. Unlike Jia and Inae, she left as early as possible after class. To the question of her social networks, she talked about her Japanese and Taiwanese friends who had been her classmates when she came to the U.S. at first. She said that she intentionally did not interact with other Korean classmates because she came to the U.S. to learn English, not for making other Korean friends. Her initial settlement in the U.S. was supported by her cousin in the same town. She expressed the language difficulty in the beginning of her stay but she valued the dynamic experience in a foreign country in terms of learning interpersonal skills and knowledge about different cultures, more than just 
improving her English. The two female students are planning to come back to the U.S. for graduate study after they complete their undergraduate programs. Both valued English learning as experiencing foreign culture and expanding the horizon of their life and perspective.

All four of the Korean students were constantly resisting their "ascribed identity" that was given to them when they arrived in the U.S. As shown in Dongseok's remarks, "I was not the person who is poor at speaking English but now I compare my English with native speakers", they get the new appellation of novice English learner in the U.S. that they never expected to be assigned in their home country. Through the change in social status and identity, they experience cultural alienation and isolation through the whole process of their language socialization. Their resistance to the shift of their social identity emerges as confusion, complaints, anger, and frustrations in the beginning of their socialization and they develop their own strategies to deal with the isolation and cultural alienation.

Hyungsoo and Mirae, who have been in the U.S. for ten months, showed a difference in dealing with moments of cultural miscommunication in classroom events from Dongseok and Jia, who have been for just three months. Whereas the newly arrived students were confused, frustrated and vigorously resisted to the change to an inferior social status in and out of the classroom, those who arrived to the US earlier perceived the difference in their "ascribed identity" in the US and the "achieved identity" that they brought from Korea and made efforts to reduce the gap between their current actual identity in the US and the designated identity that they desire to attain in the US. Hyungsoo and Mirae seemed to accept their "ascribed identity" partly; however, as revealed in Hyungsoo's last remarks, their resistance has not ended yet. They were still in the ongoing process of gaining authorization by others and obtaining the designated identity by way of getting an admission to graduate school, performing well in school work, and through other means.

\section{Concluding thoughts}

As Gee (2001) and Sfard and Prusak (2005) stated regarding identity construction, one's identity is not structured by one certain kind of identity or single event but is formed by multiple identities at the site of power struggles and the numerous social events in one's life. The change of their perception about themselves during the socializing process is intertwined with the power struggles they experienced, i.e., how their power was produced and recognized by others, how it shifted in classroom events and interactions, and how it influenced obtaining a membership in the new community. Learning and teaching are not just a way of conveying and exchanging "indexical knowledge". They are keenly intertwined with power struggles and identity conflicts in language learners and produce a new order of power, which is engendered by acquiring knowledge through power struggles in the classroom interactions. Knowledge is produced by humans and humans are empowered by the knowledge through teaching and learning.

With a shift of power and privilege, learners' identity and positionality are shifted to maintain and protect their own identity by resisting ascribed identity. The identity construction is an ongoing process that is continuously shaped and formed at the site of power struggles. The struggles to reduce the gap between ascribed identity and achieved identity are revealed in various ways based on the learners' socio-cultural capital which they bring to the classroom as a form of value, belief and identity. Through the entire learning process, learners construct a new identity and obtain a membership of the community by acquiring knowledge and negotiating their subjectivities.

\subsection{Discussions and future research}

Exploring the Korean students' life and their socialization process was a very intriguing experience. The inferior "ascribed identity" that they did not even notice in the beginning of stay in the U.S. was negotiated and compromised through the moments of their socialization process in the ESL classroom. Through the dynamics of power relations among individuals, groups, and institutions, the language learners were resisting, compromising 
Kim, J.

and negotiating the power, knowledge and their identity. Teaching and learning are not just an exchange of certain types of knowledge. They are keenly intertwined with power struggles and identity conflicts of language learners. Knowledge is produced by humans and humans are empowered by the knowledge through teaching and learning.

For future research, investigating the relation between language ideology that the Korean learners built previously and their socialization process will be worthwhile to understand their new identity formation. As discussed by Song (2007) in Korean learner's ideology of English, ideologies enact ties of language to identity and through the link they underpin the very notion of the person and the social group, as well as their socialization (Woolard, 1998). Furthermore, in order to grasp the nature of their social networks, the density and multiplicity of the networks that they constructed in the U.S. should be examined, as well. Exploring the intertextual and intercontextual relations among language ideology, social networks, and their emerging identities would help to understand the process of L2 learners' learning socialization and identity formation as a language learner.

\section{Reference}

Bloome, D., Carter, S. P., Christian, B. M., Otto, S., \& Shuart-Faris, N. (2004). Discourse analysis and the study of classroom Language and literacy events: A micro-ethnographic perspective. New Jersey: Lawrence Erlbaum Associates.

Cummins, J. (1996). Negotiating identities: Education for empowerment in a diverse society. Ontario: California Association for Bilingual Education.

Gee, J. (2001). Identity as an analytic lens for research in education. Review of Research in Education, 25, 99-125.

Heller, M. (1987). The role of language in the formation of ethnic identity. In J. Phinney \& M. Rotheram (Eds.), Children's ethnic socialization (pp.180-200). Newbury Park, CA: Sage.

Ivanic, R. (1998). Writing and identity: The discoursal construction of identity in academic writing. Amsterdam: John Benjamins.

Kim, J. (2009). Korean students' language socialization in American ESL programs. Tesol Resource Center, Retrieved April 28, 2009, from http://www.tesol.org/s_tesol/trc/trc_submission_detail_new.asp?id=873

Lave, J., \& Wenger, E. (1991). Situated learning: Legitimate peripheral participation. New York: Cambridge University Press. http://dx.doi.org/10.1017/CBO9780511815355

Peirce, B. N. (1995). Social identity, investment, and language learning. TESOL Quarterly, 29, 9-31. http://dx.doi.org/10.2307/3587803

Peirce, B. N. (1997). Language, identity and the ownership of English. TESOL Quarterly, 31(3), 409-429. http://dx.doi.org/10.2307/3587831

Pierce, B. N. (2000). Identity and language learning: Gender, ethnicity and educational change. Essex: Pearson Education Limited.

Sfard, A., \& Prusak, A. (2005). Telling identities: In search of an analytic tool for investigating learning as a culturally shaped activity. Educational Researcher, 34(4), 14-22.

http://dx.doi.org/10.3102/0013189X034004014

Song, J. (2007). Language ideologies and identity: Korean children's language socialization in a bilingual setting. Unpublished Doctoral dissertation, The Ohio State University, Columbus.

Walkerdine, V. (1990) Schoolgirl fictions. London: Verso.

Woolard, K. (1998). Language ideology as a field of inquiry. In B. Schieffelin, K. Woolard, \& P. Kroskrity (Eds.), Language ideologies: Practice and theory. Oxford: Oxford University Press. 


\section{Appendix}

Transcript Notations

$=\quad$ closely latched speech

// notes the point at which one speaker overlaps another

* * notes a softly spoken utterance or word.

((comment)) non-verbal action or transcriber's comment

(1.0) pauses in seconds

( ) indicates an unheard utterance. Parentheses that are filled indicate an uncertain hearing. 
Kim, J. 